\title{
Assisting the Long-Term Unemployed: Results from a Randomized Trial
}

\author{
Robert Breunig ${ }^{1}$ \\ Centre for Economic Policy Research \\ Australian National University \\ Deborah A. Cobb-Clark \\ Social Policy Evaluation, Analysis, and Research Centre \\ Australian National University \\ Yvonne Dunlop \\ Centre for Strategic Economic Studies \\ Victoria University of Technology \\ Marion Terrill \\ Department of Family and Community Services
}

September 17, 2002

\footnotetext{
${ }^{1}$ We wish to thank Bonny Parkinson for research assistance. We also wish to thank Jeff Borland and participants in the December 2001 Australian Labour Market Research Workshop for comments on an earlier draft of the paper. Seminar participants at the Australian National University and at EUREQUA, Paris I provided useful feedback. The comments of an anonymous referee have also improved the paper. None of the views expressed in this paper necessarily represent the views of the Department of Family and Community Services. Corresponding author: Robert Breunig, CEPR, RSSS, Building 9, Australian National University, Canberra, ACT 0200, Australia. Phone: 61-2-6125-2148. Fax: 61-2- 6125-0182. E-mail: robert.breunig@anu.edu.au.
} 


\begin{abstract}
Welfare reform in Australia centres on the concept of both economic and social participation. The policy concern is that people who fail to participate in economic and social life may become entrenched in disadvantage. In 2000 - 2001, a randomized trial was conducted by the Department of Family and Community Services in order to assess whether an intensive interview with successive follow-ups would result in increased economic and social participation for unemployed individuals who had been on income support for more than five years. We find evidence that participation in the trial led to a reduction in average weekly hours of work, but increased the amount of hours spent in study or training programs and the proportion of individuals engaged in such programs. We also find evidence of increased social integration associated with participation in the trial.
\end{abstract}




\section{Introduction}

In the face of historically high levels of unemployment in many countries, there is mounting international evidence that unemployment is increasingly concentrated among a subset of individuals who spend substantial periods of time without work. Much of the dramatic increase in unemployment over the 1970s and 1980s, for example, can be attributed to increases in the average time spent unemployed rather than an increased propensity to be unemployed (for example, Layard, et. al., 1991; Meyer, 1995; Dolton and O'Neill, 1995). The policy response has been a dramatic increase in the use of active labour market policies-for example, training or job search assistance-to stimulate the employment of unemployed workers. In this paper we evaluate the effects of one such policy (increased monitoring and counseling) on the economic and social participation of the long-term unemployed in Australia.

Australia provides an interesting case study in the growing literature evaluating active labor market policies. First, Australia has not been immune from the problem of persistent unemployment with 14.4 per cent of unemployed Australians having been unemployed for more than two years (Dockery and Webster, 2001). ${ }^{1} \quad$ Second, in spite of a similar income level and labour market environment as other OECD countries, important institutional differences in the Australian income-support system add depth to the existing literature. In Australia, unlike in many other countries, unemployment benefits are non-contributory, funded from general revenue, and comprise one component of a broader system of incomesupport payments administered by the Department of Family and Community Services (FaCS). Finally, there has been a willingness on the part of FaCS to use randomized trials to evaluate the effects of particular intervention strategies.

Between September 2000 and April 2001, FaCS ran three randomized trials involving interviews with 10,504 income-support recipients to determine whether expanded counseling and monitoring would result in increased economic and social participation. The interventions were fairly modest and were targeted towards individuals who are in some sense outside the mainstream of service delivery. ${ }^{2}$ This paper reports results of one of these trials in which unemployed people on income support for five years or more were requested to undergo a counseling and monitoring process. We match participant survey

\footnotetext{
${ }^{1}$ Miller (1997) concludes that in Australia unemployment is also increasingly concentrated within the same family units. In 1974, 8.6 per cent of all unemployment occurred in couple families where both partners were out of work. By 1994 this had risen to 23.8 per cent.

${ }^{2}$ The groups targeted included older individuals of working age, unemployed people on income support for more than five years, and jobless parents of school-aged children.
} 
data to administrative benefits data to address the following question: does an intensive interview with follow-ups lead the very long-term unemployed to increase their level of economic and social participation? Since the intervention is fairly modest and the analysis time frame short, we are concerned not only with movement off payments, but also with any deeper engagement in the social and economic life of the community which may lead to decreased dependence on the social welfare system in the future.

Our results indicate that people participating in the intensive interview process engaged in higher levels of study and training. We also find that the proportion of people who engage in study and training increased due to the intervention. Consistent with this result, individuals who participated in the full intervention are more likely to remain on payments. Hours worked fell as a result of the intervention, but we find no change in either average earnings or in the proportion of individuals engaged in paid work. Finally, the level of social engagement increases for those who participate in the intervention.

The remainder of this paper reviews the Australian income-support system and the trial itself. It then moves on to consider the methodology used to evaluate the randomized trial and the results. We conclude by discussing these results in the context of international experience.

\section{The Australian Income-Support System}

The Australian income-support system is quite different to systems in other parts of the world, which are most often based upon a social insurance model. The Australian system is non-contributory and funded from general revenue. Payment levels are uniform across the country-irrespective of previous work history-and are determined by individual circumstances such as marital status, number and age of dependent children, income and assets. In-work benefits for low-income workers are a significant feature of the system, particularly for people with dependent children.

An ongoing process of welfare reform has made economic and social participation the focal point of income-support policy. Australian policy makers increasingly embrace the notion of "mutual obligations" and are demanding more of income-support recipients. Many recipients now face a requirement to fulfill their "obligations" through work (either paid or voluntary), job search, or education. Economic and social participation is seen more generally as the primary mechanism for avoiding the persistent disadvantage accompanying long-term receipt of income support.

Obligations placed upon the unemployed and enforcement of job search requirements 
are most intense in the first 12 months of a spell of unemployment. After that, there is only a weakly-enforced obligation of continued job search. As a result, the intensity of contact with officials declines and there is little information about the activities and outcomes of the long-term unemployed. In addition to evaluating the intervention, the randomized trial also provided the opportunity to gather data and learn about this group.

\section{The Trial: Assisting the Long Term Unemployed}

The randomized trial targeted unemployed individuals (currently on Newstart Allowance) who had been on income support for five years or more. There are currently around 79,000 unemployed Newstart Allowance recipients in this situation, and this group is thought to be the most disadvantaged of all long-term income-support recipients. The proportion of people on unemployment benefits who are out of work for long periods has grown, despite a downward trend in the overall level of unemployment. Other than an administrative review people who have been on payment for more than 12 months tend to have little contact with Centrelink and receive only minimal assistance in addressing their employment barriers. The question of interest is whether an intensive interview with Centrelink staff would be helpful in improving economic and/or social participation.

The process of the trial was as follows. Twenty Centrelink sites were chosen randomly across Australia. Next, a list of clients meeting the selection criteria was randomly selected from those sites. This resulted in the selection of 4740 participants, who were then randomly allocated to control and intervention groups.

Centrelink sent a letter to each individual selected for the intervention group, asking her or him to attend an interview. This letter formed one part of the intervention. ${ }^{3}$ The full intervention consisted of the letter and two face-to-face interviews. The first of these interviews took place in September or October 2000. Interviews were conducted by Centrelink staff who had been trained in research interviewing techniques and who administered a detailed questionnaire eliciting information about the individual's employment and educational background, current circumstances, goals and aspirations regarding economic and/or social participation, and any barriers to increased participation. The interviews and the data gathered went well beyond the usual employment-oriented survey

\footnotetext{
${ }^{3} \mathrm{~A}$ copy of the letter is in Appendix 2. In all, seven letters were sent to control and intervention group participants at different waves of the survey/intervention. Copies are available from the authors. Letters were sent to those who declined to be interviewed and to those who had no phone number in the Centrelink records in an attempt to solicit greater participation. See the discussion of dropout in the methodology section below.
} 
and included detailed questions about the level of interaction which individuals had with their families and local communities and their view of themselves within Australian society. Participants and interviewers discussed ways in which the participant could become more economically and socially integrated and jointly developed a Participation Plan, codifying the agreements made in the discussion.

A second interview - to find out how individuals' situations had changed and to determine take up of referrals from their Participation Plans - was conducted in November and December 2000. A final 20-minute telephone interview was conducted by an independent market research company in March and April 2001. Comparison of data from the first face-to-face interview (Wave 1) and the follow-up telephone interview (Wave 3) forms the basis of the analysis of the impact of full participation in the trial. Full treatment is defined for the purpose of this study as receipt of the letter and participation in both face-to-face interviews. Those who received the letter but did not participate in both interviews are considered as having received partial treatment. ${ }^{4}$

In September to October 2000, control group members were sent letters informing them of the proposed interview process. Those who agreed were interviewed at the same three points in time as the intervention group by the same market research firm that conducted the final intervention group interviews.

In addition to detailed survey information, we made extensive use of administrative data, from FaCS's Longitudinal Data Set (LDS), which was merged with the trial survey data. LDS provides fortnightly observations on benefits and limited demographic characteristics (age, age of youngest child, geographic area, etc.). The fact that these administrative data are available for all individuals selected for the trial (irrespective of whether or not they participated) allows us to test random assignment and to assess the factors related to an individual's decision to fully participate in the treatment (or in the case of the control group to agree to be interviewed in all three waves). In the following sections, we discuss in more detail how the administrative data were used.

\footnotetext{
${ }^{4}$ The receipt of the letter may itself affect individuals. For example, Black et. al., (1999) and Richardson (2001) conclude that contact between payment recipients and funding organizations often leads recipients to change their behaviour even in the absence of any actual training or other program. Given that this is a group of the long-term unemployed - for whom no contact with the government agency distributing their payments is the norm - any contact must appear unusual and may alter their behaviour.
} 


\section{Methodological Issues and Estimation Strategy}

The randomized design of the trial was intended to simplify the measurement of the impact of the intervention on the outcomes of interest. To illustrate, we begin by letting the population relationship between an outcome, $Y$, and some characteristic, $X$, for people when they do not participate in the intervention be given by

$$
Y^{0}=X \beta_{0}+u_{0}
$$

where $E\left[u_{0} \mid X\right]=0 .^{5} \quad$ Likewise, the population relationship between $Y$ and $X$, for people when they do participate is given by

$$
Y^{1}=X \beta_{1}+u_{1}
$$

where $E\left[u_{1} \mid X\right]=0$. The superscripts on $Y$ indicate the outcome under participation and non-participation. We will suppress these whenever possible. We refer to realizations of the outcome measure for participants and non-participants as $y^{1}$ and $y^{0}$, respectively.

Given this framework, there are several parameters which might be of interest when considering the impact of treatment on individual outcomes. The average treatment effect,

$$
\Delta^{A T E}=E\left(Y^{1}-Y^{0} \mid X\right)
$$

measures the change in expected outcomes across the entire population as a result of participation in the intervention. When only some individuals in the population receive the treatment - for example because the intervention is voluntary or because resource constraints limit the number of individuals able to be treated - the effect of "treatment on the treated" can be defined as

$$
\Delta^{T O T}=E\left(Y^{1}-Y^{0} \mid X, P=1\right)
$$

where $(P)$ which takes value 1 if the person participated in the intervention and 0 otherwise. This latter parameter is often of greater interest since this measures the effect of the treatment for those people who actually do participate in the treatment. The challenge in deriving estimates of these two parameters, however, is that we do not observe both $y^{1}$ and $y^{0}$ for any particular individual. This is the well-know "evaluation problem" (Heckman et al., 1999).

Random assignment provides one means of solving this evaluation problem. To see this, define a dummy variable $(S)$ which equals 1 if the person is randomized into

\footnotetext{
${ }^{5}$ The linear outcome equation is not particularly restrictive, but is used merely for ease of exposition.
} 
the intervention group and 0 if randomized into the control group. With no dropouts and obligatory participation, $P=1$ whenever $S=1$. Assuming sample sizes of $n_{0}$ and $n_{1}$ in control and intervention groups respectively, one possible estimator of the average treatment effect is

$$
\begin{aligned}
\widehat{\Delta}_{1} & =\bar{y}^{1}-\bar{y}^{0} \\
& =\frac{1}{n_{1}} \sum_{i=1}^{n_{1}} y_{i}^{1}-\frac{1}{n_{0}} \sum_{j=1}^{n_{0}} y_{j}^{0} .
\end{aligned}
$$

It measures the effect of taking a randomly selected individual from the population and treating him or her. Under the assumption that all people assigned to the intervention group fully participate in the treatment, $\widehat{\Delta}_{1}$ also captures the effect of treatment on the treated. If only some individuals selected into the intervention group receive treatment this is no longer true (see Heckman et. al., 1999).

FaCS's initial intention was to conduct a randomized trail in which all individuals were required to participate and then subsequently use $\widehat{\Delta}_{1}$ to measure the resulting change in outcomes (the average treatment effect). Randomization allows us to analyze results without controlling for the covariates, $X{ }^{6}$ Whether treatment effects are homogenous or heterogenous across individuals does not particularly matter, and $\Delta^{A T E}$-as estimated by $\widehat{\Delta}_{1}-$ can be seen as the expected treatment effect averaged across all individuals.

Several practical difficulties arose in the trial which cast doubt upon the validity of $\widehat{\Delta}_{1}$ as the appropriate estimator, however. First, examination of the data suggested that the initial assignment into control and intervention groups had not been random. Furthermore, significant dropout took place from both the treatment and the control groups. Control group dropout is an uncommon problem and has not been addressed in the literature. Both dropout processes are likely to be correlated with outcomes. Where dropout is correlated with outcomes, the simple mean comparison is no longer an unbiased estimator of the average treatment effect. Finally, different data gathering techniques were used for treatment and control groups for the first two waves. There may be systematic differences in how individuals respond to different interview techniques even

\footnotetext{
${ }^{6}$ To see that this is an unbiased estimator in a randomized trial, consider a regression framework where $\Delta_{1}$ is the coefficient on $P$

$$
y=\alpha+\Delta_{1} P+v .
$$

$v$ includes $X$, but provided the randomization is properly carried out

$$
E(P \mid X)=E(P \mid v)=0 .
$$


for identically posed questions. We discuss each of these issues in turn in the remainder of this section.

\subsection{Randomization}

In order to use the simple mean comparison of (5), the treatment and control groups must be randomly chosen samples from the population. Using administrative data from the LDS, we tested whether the means of key demographic variables for the full intervention group of 2940 individuals were the same as those of the 1800 individuals in the control group. The characteristics-in particular age and income levels-of individuals in the two groups were quite dissimilar suggesting that the initial sample assignment had not achieved randomization. (See Table 1, columns 2 and 3).

Investigation into the procedure used for the sampling provided some insight into the source of the problem. FaCS, in addition to this trial, was simultaneously conducting a similar study of mature-aged payment recipients. Because of concerns about potentially small sample sizes for that trial, last minute alterations were made to the sampling frame for this study. As a result, no individuals over the age of 50 were assigned to the control group, although about 10 per cent of the individuals in the intervention group are over age 50. It seems unlikely that this discrepancy arose by chance. For obvious reasons, age is an important factor in determining the outcomes of interest, thus (ii), in footnote 6 , will be violated.

\section{[Table 1 about here]}

Unfortunately, dropping those aged 51 and over from the intervention group was not sufficient to rescue the random assignment. Using the LDS, we compare the means of key variables for the age-restricted intervention group and the full control group in column 4 of Table 1. These results indicate that there remain many significant differences between the means of important variables which may be correlated with outcomes, suggesting that the randomization may have also failed in other significant ways. ${ }^{7}$

Further investigation revealed the mode of data collection to be the problem. Those individuals drawing the sample recognized that data from the control group were to be collected via phone interviews. Consequently, any individual assigned to the control group who did not have a phone number registered with FaCS was discarded from the control group. ${ }^{8}$ Surprisingly, around 50 per cent of all payment recipients have not registered a

\footnotetext{
${ }^{7}$ For age and earnings, we compare the entire distribution of the variable using a Kolmogorov-Smirnov test. (See Ashenfelter, Ashmore, and Deschênes (1999)). We reject the equality of the distributions.

${ }^{8}$ This is unrelated to the age problem. Reporting a phone number is positively correlated with age.
} 
phone number. In modern society, the lack of a phone is likely to pose a large barrier to economic and social connectedness. Not reporting a phone number, of course, is something quite different, but there may be systematic differences between people who report phone numbers and those who do not. This breakdown in random assignment leads $\widehat{\Delta}_{1}$ to be a biased estimator for the average treatment effect.

The results of randomization tests for the sample of individuals in the intervention group under 51 years of age with a recorded phone number are presented in column 5 of Table 1. This restricted sample exhibits only insignificant variation from the control group for all the variables considered. Furthermore, we fail to reject that the age and earning distributions are the same across the two groups. We considered-and rejectedthe possibility that mean characteristics are now not significantly different because of the increased standard errors which arise from the smaller sample size. ${ }^{9}$ Randomization thus appears to hold for this subsample of the data. The large reduction in sample size necessary to use the random experiment framework (from 409 Wave 3 intervention group participants to 239) is an unfortunate consequence of the failure to achieve randomization in the initial assignment. Table 2 provides the original sample sizes which were selected, the reduction in sample size implied by the age only and phone and age restrictions, and the attrition in sample size from Wave 1 to Wave 3 . The different arrows from the population to the selected samples indicate that different processes were used to draw the samples and that they are not, in fact, random.

\section{[Table 2 about here]}

\subsection{Dropout}

An additional challenge for the experimental nature of the trial is the large numbers of people who were assigned into both the control and intervention groups, but who chose not to participate in the entire sequence of interviews. ${ }^{10}$ In order for $\widehat{\Delta}_{1}$ to be an unbiased estimator of the average treatment effect, it must be the case that the decision to drop out is unrelated to those individual characteristics influencing outcomes. Correlation between the decision to fully participate once selected and individual characteristics can easily confound the effects of those characteristics and full program participation on outcomes.

\footnotetext{
${ }^{9}$ We informally checked this using the standard errors from the larger sample size with the estimates from the smaller sample size.

${ }^{10}$ Although the language of compulsory attendance in the initial letter was strong, there was little effort made to penalize individuals who did not come in for an interview. Others who received letters contacted Centrelink by telephone and were told they did not actually have to attend interviews. Only limited records of these 'exemptions' and the reasons they were given were kept and we are therefore unable to distinguish between 'non-response' and 'dropout.' We will refer to all these as 'dropouts.'
} 
Dropout in and of itself is not a severe problem. ${ }^{11}$ One solution is to consider the "effect of the intention to treat" by comparing average outcomes for the entire intervention group to average outcomes for the entire control group. This is a parameter of interest that can easily be calculated in the face of treatment dropout and, in many cases, may better capture the true expected impact of a new policy. Since any policy is likely to be imperfectly and incompletely implemented, including dropouts as well as those who are successfully fully treated provides a more realistic estimate of expected changes in outcomes resulting from the policy initiative. Furthermore, since Centrelink-which implemented the intervention-would also be charged with implementing any new policy, this "effect of the intention to treat" would in fact capture the impact of the actual contractual arrangements and incentive structures which would exist under any new policy. ${ }^{12}$ As Reicken and Boruch (1978) note, "a carefully designed experiment with carelessly implemented treatments" may be the wisest method for exploring social innovation.

In our case, the main difficulty arises because we lack survey data for intervention and control group members who chose not to participate in an interview (or who were unable to be contacted). While FaCS was able to deal with any ethical concerns associated with random assignment, legal and ethical constraints regarding data privacy precluded data collection from those individuals opting out of the interview process. The magnitude of the dropout problem is quite substantial, as evidenced by Table 2, and as we discuss below, this makes the evaluation problem much more difficult. Fortunately, however, we can go some way towards addressing this problem by merging survey data to administrative payments data for individuals selected for the trial. This is discussed in section 4.4.

\subsection{Interview Technique}

It is also important to note that different data gathering techniques-i.e., face-to-face or via telephone--were used for the intervention and control groups in Waves 1 and 2. Wave 3 data were gathered by the same market research firm in the same way for both groups. (See Table 2.) Systematic differences in responses across the groups may therefore be due to the survey technique itself and not due to the effect of the intervention. As we note below, this will complicate the interpretation of the results to a degree. ${ }^{13}$

\footnotetext{
${ }^{11}$ See Heckman et al., (2000).

${ }^{12}$ See Barrow (2000) for U.S. evidence on this point.

${ }^{13}$ One difficulty arises from the trial being conducted by Centrelink staff whose normal function is to assist customers with income-support needs. This raises the common problem that while keen and committed for the most part, many of these staff may have unintentionally subverted the experimental design of the project because of contrary beliefs about what was best for the customer. (Riecken and Boruch, 1978 discuss this problem in the context of ecological experiments carried out by environmentalists.)
} 


\subsection{Estimation Strategy}

We adopt a two-pronged estimation strategy. First, the survey data from the trial will be used to construct the principle outcomes to be evaluated. These data are only available for those individuals participating in all waves of the survey, however. In what follows, therefore, we will focus on developing an estimation strategy to identify the "effect of full treatment on the fully treated" using this survey data. Second, we will estimate the "average treatment effect" and the "effect of intention to treat" using the administrative data which has subsequently become available. This requires complete outcome data for all participants. Therefore, using LDS data through June, 2001, we construct simple outcome measures for all individuals selected into both intervention and control groupseven those who did not participate in any part of the survey. If individuals no longer appear in the LDS database-i.e. have they moved off payments-then this itself may be considered as one outcome.

For LDS-based outcome measures we use the randomized experimental estimator of (5) on the subset of the data for which randomization holds: i.e., the control group compared to the age and phone restricted intervention group. Estimation of the effect of full treatment on the fully treated from the survey data, however, will require a more sophisticated strategy. It is to this that we now turn.

The comparison we wish to make is between those who fully participated in the intervention and those in the control group who would have fully participated had they been selected for the intervention. This entails estimating an altered version of (4),

$$
\Delta_{2}^{T O F T}=E\left(Y^{1}-Y^{0} \mid X, P^{*}=1\right)
$$

where $P^{*}=1$ when an individual completes the entire treatment and 0 otherwise. This is the effect of treatment on the fully treated. The practical difficulty in estimating this parameter is that we need to determine which control group members would have participated in the treatment had they been assigned to the intervention group.

Sample selection models (Heckman, 1979) and matching estimators (see Smith and Todd, 2000 and Blundell and Costa Dias, 2000) both provide ways to estimate (6). In this paper, we adopt a matching estimator approach because it allows us to account for dropout without overly restrictive structural assumptions (see Heckman, et. al., 1997). The basic idea is to match intervention group members participating in the full treatment with control group members who have similar characteristics. If observable characteristics capture all key determinants of participation, then differences in outcomes for the matched 
individuals may be attributed to the intervention. The hope is that those control group individuals (with similar observed characteristics) would also have participated in the full treatment had they been randomized into the intervention group. We thus deal with the problem of not observing $P^{*}$ when $S=0$ and this allows estimation of "full treatment on the fully treated"-the effect of complete program participation on those who choose to participate.

To implement this strategy we use the LDS data to combine multiple characteristics into a "propensity score" which summarizes the relationship between participation and individual characteristics. Specifically, for the intervention group, we estimate a logit model of the probability of participating in the full treatment as follows

$$
p_{i}^{I}=F\left(z_{i}^{\prime} \delta_{1}\right)
$$

where $p_{i}^{I}$ takes value 1 if an individual fully participates in the treatment, $p_{i}^{I}=0$ whenever the person drops out at any point in the treatment, and $z_{i}$ are characteristics from the administrative data. Using these estimates, we can create the propensity score (predicted probability) for each individual in the intervention and the control groups. Individuals with similar propensity scores have similar probabilities of complete participation in treatment. We then use the matched data to estimate

$$
d_{i}=y_{i}^{1}-y_{i^{*}}^{0}
$$

where the outcome for individual $i$ in the intervention group, $y_{i}^{1}$, is compared to the outcome for his or her counterpart(s) $i^{*}$ in the control group. Each intervention group member can be compared to a single individual in the control group or to multiple control group members. We employ kernel propensity score matching, which involves taking a weighted average of multiple control group individuals with propensity scores similar to the specific individual in the intervention group. Weights are positively related to the similarity in the propensity scores for the specific control group member under consideration and the intervention group member for whom we are seeking a match. The difference estimator for individual $i$ is then

$$
d_{i}=y_{i}^{1}-\frac{1}{n_{o}} \sum_{j=1}^{n_{o}} K\left(\frac{\widehat{p}_{i}^{I}-\widehat{p}_{j}^{C}}{h}\right) y_{j}^{0}
$$

where $\widehat{p}_{i}^{I}$ is the propensity score from (7) for individual $i$ in the fully treated group, $\widehat{p}_{j}^{C}$ is the propensity score from (7) for individual $j$ in the control group, and $y_{j}^{0}$ is the observed 
outcome for that individual. ${ }^{14}$

In order to interpret the matching estimator as a measure of the impact of full treatment on the fully treated, we make a critical (though standard) conditional independence assumption. That is once observable characteristics have been accounted for, outcomes are assumed to be independent of participation status. ${ }^{15}$ Second, we also require that the common support condition holds and that there is some range of observable values of $X$ that are common to both the control and the intervention groups.

Given random assignment and full participation the common support condition would hold trivially. While randomization seems to hold for the age and phone restricted samples, dropout from the control group remains a problem. In the face of differential dropout from the control group, we can no longer assume that the common support condition will hold in Wave 3 when we measure outcomes-even if we have random assignment. We investigate this by estimating a logit model of the probability of remaining in the sample at Wave 3 separately for the intervention and control groups. (See Table A1 in Appendix 1). Using a likelihood ratio test, we are unable to reject the hypothesis that the two participation processes are the same. ${ }^{16}$ Further, Figure 1 provides nonparametric density estimates of the propensity scores for the intervention and control group. Their similarity provides evidence that the common support condition holds.

We are somewhat less sanguine about the conditional independence assumption. The administrative data used to generate the propensity scores are lacking several key variables that would seem to be important in accounting for participation. However, Augurzky and Schmidt (2001) argue that the success of propensity score matching does not depend necessarily upon having a consistent estimator of the selection equation (in contrast to the standard, parametric selection model discussed further below). Mis-specification of the participation equation does not invalidate the matching procedure so long as important variables affecting both participation and outcomes are controlled.

\footnotetext{
${ }^{14}$ We use a standard normal kernel for the weight function $K$ and a bandwidth, $h$, chosen by using Silverman's (1986) suggested robust bandwidth for density estimation. We tried bandwidths ranging from .001 to .05 and the results are insensitive to choice of bandwidth.

${ }^{15}$ This assumption is discussed in detail elsewhere. See Smith and Todd (2000) and Blundell and Costa Dias (2000).

${ }^{16}$ We also find no significant difference in the participation process in Wave 1 for the two groups.
} 


\section{The Impact on Social and Economic Participation}

\subsection{Results from the Survey}

Our focus is on five specific outcome measures from the intervention survey: paid work, job search, study and training, voluntary work, and social integration. ${ }^{17}$ We begin by considering the survey results for Wave 3 participants. For each activity, we will consider total hours and participation levels. We also estimate a combined measure of job marketrelated activity which aggregates the first three outcomes. The left-hand side of Table 3 contains the estimated impact of the intervention on hours while the right-hand side provides the effect on participation.

For each activity, we present the intervention group average, which is based upon the sample average of the age and phone restricted group, and a weighted control group "average" based upon the matched individuals from the control group. The estimated impact of the intervention is

$$
\widehat{\Delta}_{2, \text { Wave } 3}=\frac{1}{n_{m}} \sum_{i=1}^{n_{m}} d_{i, \text { Wave } 3}
$$

where $d_{i}$ is given by (9) measured using the data at Wave 3 and $n_{m}$ is the matched sample size. ${ }^{18}$ We refer to this as the "cross-sectional" estimator since it is based upon comparison of control and intervention groups at one point in time (Wave 3).

\section{[Table 3 about here]}

The intervention resulted in a significant positive effect on study or training. ${ }^{19}$ The number of hours spent in study or training each week was higher for intervention than control group members and there was a significant 5.3 per cent difference in the proportion of individuals who took up study or training between the two groups. This appears to be the result of people undertaking study and training activities which were agreed to in the Participation Plans formed during the initial face-to-face interview.

Intervention group members also had a higher rate of social integration. The partici-

\footnotetext{
${ }^{17}$ We define social integration as a dummy variable which equals 1 for people who meet socially with friends more than once a week or who belong to a club or community association and 0 otherwise.

${ }^{18}$ We drop observations for which there is no 'good' match. This is defined as observations for which there are no similar propensity scores in the control group. In our estimates we never drop more than two observations.

${ }^{19}$ In our analysis, we compare outcomes from full treatment to outcomes for individuals in the control group. If one is willing to assume that being in the control group does not affect behaviour, then we can think of this comparison as being between full treatment and no treatment. Given the previous discussion about the effect of receiving a letter for this group of long-term unemployed, it may be better to view this as a comparison of two different kinds of treatment. The treatment for the control group is receipt of a letter and the data gathering process itself.
} 
pation rate in social activity with friends or club membership was 7.5 per cent higher for the intervention group than for the control group. These propensity score matching estimators control for differential dropout processes in the control and intervention groups. They are based upon the age and phone restricted sample since we feel that this is the group for whom the assumptions required for the matching estimator to be valid are most likely to hold. Despite the focus of numerous questions on voluntary activity, we find no significant effect on hours or participation in voluntary work from the intervention.

The intervention led to a significant reduction in the reported hours worked by the intervention group, though there is no significant difference in participation in paid work between the two groups. The hours result may be driven by a differential tendency to under-report as a result of the intervention. Control group members knew they were not being interviewed by Centrelink. Intervention group members were told that a benefit review was part of the interview process, creating some incentive for under-reporting of hours worked. Even though the Wave 3 data were collected by a market research firm for both intervention and control groups, it is possible that this incentive to under-report hours worked remained since intervention group members were aware that this third interview was a continuation of the treatment and data collection process.

\subsection{Results from Administrative Data}

Availability of the LDS provides an opportunity to examine longer-term outcomes and to examine outcomes for all individuals assigned to the intervention group, including those who chose not to participate. Recently, FaCS has made available further LDS data which extend through 28 June 2001-two months beyond the end of the trial. Future releases of the LDS will provide additional opportunities to examine the outcomes beyond this date.

Using data through 28 June 2001 does not add much in terms of time to the observation window, but it does allow us to answer several important questions which can not be addressed using the survey data. Did assignment to intervention or control group, irrespective of participation in the trial, have any effect on outcomes? Were outcomes different for those who fully participated in the trial, compared to an average individual ${ }^{20}$ We can also use the administrative data to create further measures of "full treatment on the fully treated"-provided that selection into Wave 3 control and intervention group participation is the same.

\footnotetext{
${ }^{20}$ These correspond to the "effect of intention to treat" and "treatment on the treated" discussed above.
} 
Focusing on these questions, we consider five outcomes: movement off payments and to a different payment type, presence of earned income, average earned income, and average earned income for those with income. We use average values over the last two fortnights of data (1 June through 28 June, 2001) to construct each outcome measure in order to eliminate high-frequency variation ${ }^{21}$. We compare the control group to the intervention group restricted by phone and age since we believe randomization holds across these two groups. The second column of Table 4 addresses the effect of intention to treat. We do not find any significant difference in outcomes between those assigned to the intervention and control groups. The third column of Table 4 compares the intervention group for whom we have Wave 3 data (the fully treated) to the full control group. This corresponds to treatment on the treated-comparing those who fully participated to an average individual and allowing the decision to participate to be part of the effect. For this group, we find that intervention group members are more likely to remain on payment and are more likely to still be receiving Newstart allowance. ${ }^{22}$ This is not surprising. We know that intervention group members are more likely to have enrolled in study or training programs. These programs are compatible with continuing receipt of payments and participation in such programs may mean that people are less likely to leave payments for employment. Although the short term effect of this may be that program participants are more likely to remain on payments, it is possible the long run effect may be to move people off payments more effectively. Furthermore, additional study and training is expect to help people move to better quality outcomes when they leave payments. Future study of the LDS should be enlightening in this regard.

\section{[Table 4 about here]}

Comparison of Wave 3 control and intervention groups is in column four. The patterns of significance are the same as for our estimate of "treatment on the treated." Interestingly, we find further confirmation of our result from the survey data that average earnings and the proportion of people with paid work are not affected by the intervention.

\subsection{The Robustness of the Results}

In addition to the cross-sectional propensity score matching estimator, we consider three other estimators of the intervention impact: the cross-sectional randomized experiment

\footnotetext{
${ }^{21}$ People often leave the data for one fortnight only to return soon thereafter. This may not be reasonably viewed as movement off payment.

${ }^{22}$ Movement to disability payment or parenting payment single were the two most common nonNewstart payments for both intervention and control groups.
} 
estimator (5), a difference-in-differences (DID) estimator

$$
\widehat{\Delta}_{1, D I D}=\left(\bar{y}_{\text {Wave3 }}^{1}-\bar{y}_{\text {Wave } 1}^{1}\right)-\left(\bar{y}_{\text {Wave } 3}^{0}-\bar{y}_{\text {Wave } 1}^{0}\right)
$$

and a matching DID estimator where sample means in (11) are replaced with matched means. Appendix tables A2, A3, and A4 present all four estimates for hours of economic activity, participation in economic activity, and voluntary and social participation. The DID estimators allow for systematic differences in the initial starting levels of activity for intervention and control groups, but the assumption is that all changes over time are due to the effect of the intervention. ${ }^{23}$ The DID estimators are reported for completeness, but we prefer the cross-sectional estimators because of the change in interview methods. ${ }^{24}$

The cross-sectional randomized experimental and propensity score matching estimators are quite similar suggesting that the dropout processes in the control and intervention groups from selection to Wave 3 were in fact similar. This provides further evidence that randomization was achieved for the age and phone restricted sample.

Finally, we attempted to improve the quality of our propensity score matching by including the Job Seeker Classification Index (JSCI) score for each individual in the participation equation. Using JSCI resulted in a large decrease in sample size, since the variable was not available for all individuals, and furthermore it was not significantly related to the probability of participating in treatment. We also investigated whether the results of the matching estimates were sensitive to the choice of matching algorithm. Instead of a kernel approach, we used k-nearest neighbor (k-NN) matching with values of $k$ ranging from 1 to 30 . The results were nearly identical to the results from the kernel matching reported here ${ }^{25}$. Thus, our results appear robust to a number of alternative specifications.

\footnotetext{
${ }^{23}$ One reason to believe that initial starting levels may have in fact not been identical is that information about which sites were selected for the intervention was provided to some other government agencies. Some potential participants at those sites were chanelled into another government program which made them ineligible for this intervention. This failure of randomization might not be picked up by the variables available in the LDS, but the oberved difference in levels of economic activity at Wave 1 may be a result of this.

${ }^{24}$ The DID estimates will erroneously attribute effects from the change in interview technique (in-person to phone) to the intervention. In other work, we have analyzed the barriers to economic and social participation available in Wave 1 data. Intervention group members were much more likely to report multiple barriers which appears to be due to prompting by interviewers in the face-to-face interviews. This suggests that interview technique matters in the measurement of some outcomes.

${ }^{25}$ Full results using the JSCI score and the results of the k-NN matching are available from the authors. A standard Heckman (1979) selectivity correction model produced large and unbelievable, negative estimates of the impact of the intervention. Identification of this model requires correctly specifying both the participation and outcome equations and including all relevant variables in the estimation. It also relies upon strong parametric assumptions. We conclude that the assumptions necessary for the matching estimator to generate valid estimates are much less burdensome, and much more likely to be met, than those needed for the structural modelling approach. (See Augurzky and Schmidt, 2001.)
} 


\section{Discussion}

It is useful to put these results in the context of the growing international literature on active labour market program evaluation. The intensive interview process that formed the basis of the current intervention had elements of 1) counseling, 2) increased monitoring of eligibility, and 3) provision of job search assistance. "Counseling" was a major part of the intervention and took the form of referrals to educational, training, or counseling programs. Individuals were also encouraged to engage in goal setting and planning for the future. At the same time, the letter recruiting the intervention group and the establishment of regularized contact with government officials may have also affected behaviour through a type of monitoring effect. Job search assistance was not specifically an objective of the intervention, but may have formed a small part of the interview process.

We are unaware of any research specifically analyzing the effect on hours spent in training, volunteer work, or the broader measure of social participation we have considered here. Previous researchers have generally focused on evaluating the effects of such interventions on unemployment-related outcomes. Nonetheless, this literature is useful for shedding light on the results of the current study.

Björklund and Regnér (1996), Meyer (1995), and Heckman, et. al. (1999) review the results of a number of previous studies evaluating the effects of job search assistance on the unemployed using random assignment. ${ }^{26}$ Intensive job search assistance seems to significantly increase exit into employment in a variety of situations. For example, Meyer (1995) reports the results of five experiments in which increased monitoring was combined with job search assistance. In four out of five cases the benefits of the overall intervention exceeded the costs by a wide margin leading to the conclusion that a range of approaches seem to be successful. At the same time, there is evidence that enforcement or monitoring-on their own-may not be effective in altering the employment outcomes of unemployed individuals. Ashenfelter, Ashmore, and Deschênes (1999) conclude that more intensive monitoring of job search activity in the United States did not significantly reduce the length of unemployment or overall benefit receipt and that the enforcement of sanctions was not cost-effective.

Not surprisingly, both the intensity of the intervention and the degree of disadvantage faced by the target population are key factors in the measured success of monitoring, counseling, and job search assistance programs in moving unemployed individuals into

\footnotetext{
${ }^{26}$ Results based on non-experimental methods appear to result in somewhat different conclusions-at least with respect to the effects of increased monitoring (Meyer, 1995)-and will not be reviewed here.
} 
work. Relative to these previous studies, the intervention considered here is very modest indeed. Individuals undergoing the complete treatment participated in two face-to-face interviews approximately two months apart. In contrast, van den Berg and van der Klaauw (2001) evaluate a counseling and monitoring program which consisted of a 45 minute meeting with a counselor at the local unemployment agency every four weeks for six months. During these meetings, the quality of applications and resumes is examined, methods of job search are discussed, and a job search strategy for the intervening four weeks is developed. Gorter and Kalb (1996) also use Dutch data to evaluate the effectiveness of an intensive job assistance program in which-in addition to "counseling and monitoring"-counselors provided a general overview of job vacancies pointing out particularly suitable vacancies to each individual. These interventions were much more intensive than the one considered here, yet the estimated impact from each was small.

The relative degree of disadvantage-both in terms of personal job readiness and general labour market conditions-faced by unemployed individuals is important as well. In this case, although Australian labour market conditions were relatively favourable during the period in which the trial was conducted, the unemployed individuals participating in the trial were extremely disadvantaged. All were unemployed and had been on income support for at least five years, making them among the most entrenched in the Australian welfare system. Thus, it may be the case that while counseling and monitoring is relatively ineffective in increasing the rate at which unemployed individuals with relatively good labour market prospects find jobs (as in van den Berg and van der Klaauw, 2001), it appears it is also not effective for marginalized workers with larger barriers to employment.

\section{Conclusion}

Welfare reform in Australia centres on the concept of both economic and social participation. The policy concern is that people who fail to participate in economic and social life may become entrenched in disadvantage. The data gathering and randomized trial discussed here was initiated by the Department of Family and Community Services in order to assess whether an intensive interview with successive follow-ups would result in increased economic and social participation for unemployed individuals on income support for more than five years. Our evaluation of this trial suggests that this intervention was mildly successful in increasing economic and social participation. Hours of study and training are significantly greater for individuals who participated in the trial relative to the control group. A higher proportion of individuals were also engaged in study or train- 
ing in the intervention group than the control group. At the same time, reported weekly hours of work fell, though this may be a result of including a benefit review as part of the intervention. Social participation, as measured through interaction with friends and family and membership in social organizations, was higher for intervention group members than for control group members. We conclude that the intervention had no significant effect on job search, volunteer work or the proportion of individuals in employment.

That these results are modest is perhaps not surprising. In designing the intervention FaCS had no expectation that several short interviews would result in large-scale movements of the long-term unemployed into jobs and off payments. Instead the trial was intended to quantify barriers to economic and social participation and to begin to identify strategies for removing them. The result may in fact be increased social participation, which though not apparent in voluntary work, is reflected in the social integration measure we considered. It may be that such increases in social participation, even those unrelated to job skills, might put people on a path towards greater economic and social participation which will yield long-term results. The current window for observing postintervention impact is short and the observed increases in study may in future lead to increases in hours worked.

Further research addressing several questions therefore seems desirable. First, has social participation, as gauged by measures broader than the ones considered here, increased as a result of the experiment? Second, do short-term increases in social participation lead to long-term economic outcomes including movement off payments? Third, do stronger and more intensive interventions lead to changes for the very-long term unemployed? Finally, are there any long-term effects of this intervention? This latter question can be addressed by using administrative data which will become available in the future.

\section{References}

[1] Ashenfelter, O., D. Ashmore and O. Deschênes,1999, Do Unemployment Insurance Recipients Actively Seek Work? Randomized Trials in Four States, National Bureau of Economic Research working paper number 6982, February.

[2] Augurzky, B. and C. Schmidt, 2001, The Propensity Score: A Means to an End, Institute for the Study of Labour (IZA) Discussion Paper No. 271, March, Bonn.

[3] Black, D., M. Berger, B. Noel, and J. Smith, 1999, Is the Threat of Training More Effective than Training Itself? Unpublished working paper, Version of 12 November 
1999. Available at http://www.bsos.umd.edu/econ/jsmith/ex111299.PDF.

[4] Bjorklund, A. and H. Regner, 1996, Experimental Evaluation of European Labour Market Policy, in International Handbook of Labour Market Policy and Evaluation, eds. G. Schmid, J. O'Reilly and K. Schomann. Cheltenham: Elger.

[5] Blundell, R. and M. Costa Dias, 2000, Evaluation Methods for Non-Experimental Data, Fiscal Studies, 21(4), 427-468.

[6] Dockery, M. and E. Webster, 2001, Long Term Unemployment and Work Deprived Individuals: Issues and Policies, unpublished working paper.

[7] Dolton, P. and D. O'Neill, 1995, The Impact of Restart on Reservation Wages and Long-term Unemployment, Oxford Bulletin of Economics and Statistics, 57(4), 451470.

[8] Gorter, C. and G. Kalb, 1996, Estimating the Effect of Counseling and Monitoring the Unemployed Using a Job Search Model, Journal of Human Resources, 31(3), 590-610.

[9] Heckman, J., 1979, Sample Selection Bias as a Specification Error, Econometrica, $47(1), 153-161$.

[10] Heckman, J., N. Hohmann, and J. Smith, 2000, Substitution and Dropout Bias in Social Experiments: A Study of an Influential Social Experiment, Quarterly Journal of Economics, 115(2) May, 651-694.

[11] Heckman, J., H. Ichimura and P. Todd, 1997, Matching as an Econometric Evaluation Estimator: Evidence from Evaluating a Job Training Programme, Review of Economic Studies, 64, 605-654.

[12] Heckman, J., R. LaLonde and J. Smith, 1999, The Economics and Econometrics of Active Labor Market Programs, in Handbook of Labor Economics, Volume III, eds. Orley Ashenfelter and David Card. Amsterdam: North-Holland.

[13] Layard, R., S. Nickell and R. Jackman, 1991, Unemployment: Macroeconomic Performance and the Labour Market. New York: Oxford University Press.

[14] Meyer, B., 1995, Lessons from the U.S. Unemployment Insurance Experiments, Journal of Economic Literature, 33(1) March, 91-131. 
[15] Miller, P., 1997, The Burden of Unemployment on Family Units: An Overview, The Australian Economic Review, 30(1), 16-30.

[16] Richardson, L., 2001, Impact of the MOI on the Exit Behaviour of Unemployed Benefit Recipients: The Threat of Additional Activities, Unpublished working paper, Australian National University.

[17] Riecken, H. and R. Boruch, 1978, Social Experiments. Annual Review of Sociology, 4, 511-532.

[18] Silverman, B., 1986, Density Estimation for Statistics and Data Analysis. London: Chapman and Hall.

[19] Smith, J. and P. Todd, 2000, Does Matching Overcome Lalonde's Critique of Nonexperimental Estimators? Unpublished working paper. Version of 22 November 2000. Available at http://www.bsos.umd.edu/econ/jsmith/nsw112200.pdf

[20] van den Berg, G. and B. van der Klaauw, 2001, Counseling and Monitoring of Unemployed Workers: Theory and Evidence from a Controlled Social Experiment, Institute for the Study of Labour (IZA) Discussion Paper No. 374, October, Bonn. 


\section{Table 1: Randomization Tests}

\begin{tabular}{|c|c|c|c|c|}
\hline Con & l Group & & ervention Group & \\
\hline & & Full & Age & Age \& Phone \\
\hline Average of Variable & & Sample & Restricted & Restricted \\
\hline $\operatorname{Age}^{a}$ & 36.01 & $36.71 * *$ & $35.23 *$ & 35.72 \\
\hline Gender & & & & \\
\hline Female & 0.28 & $0.25 *$ & $0.25 *$ & 0.31 \\
\hline Marital Status & & & & \\
\hline Married & 0.27 & $0.23 * *$ & $0.22 * *$ & 0.26 \\
\hline Separated, widowed, divorced & 0.23 & $0.27 * *$ & $0.27 * *$ & 0.22 \\
\hline Never married & 0.50 & 0.50 & 0.52 & 0.51 \\
\hline Family Status & & & & \\
\hline Has dependent children & 0.20 & $0.16 * *$ & $0.16 * *$ & 0.19 \\
\hline Number of children & 0.49 & $0.36 * *$ & $0.38 * *$ & 0.43 \\
\hline Number of children (for those with children) & 2.38 & 2.28 & 2.33 & 2.29 \\
\hline Age of youngest child & 1.20 & $0.95 * *$ & $0.94 * *$ & 1.21 \\
\hline Age of youngest child (for those with children) & 5.93 & 5.96 & 5.73 & 6.47 \\
\hline Current Earnings (6 months to 16 June 2000) & & & & \\
\hline Has reported earnings & 0.30 & $0.23 * *$ & 0.23 & 0.28 \\
\hline Average earnings ${ }^{\mathrm{a}}$ & 65.50 & $43.19 * *$ & $42.98 * *$ & 62.13 \\
\hline Average earnings ${ }^{\mathrm{a}}$ (for those with earnings) & 215.14 & $185.37 * *$ & $184.12 *$ & 225.60 \\
\hline Country of Birth & & & & \\
\hline Australian born & 0.86 & 0.85 & 0.86 & 0.85 \\
\hline Overseas born: English speaking background & 0.05 & 0.06 & 0.06 & 0.05 \\
\hline Overseas born: non-English speaking background & 0.09 & 0.09 & 0.09 & 0.10 \\
\hline Indigenous status & 0.02 & $0.03 *$ & $0.03 * *$ & 0.02 \\
\hline Location & & & & \\
\hline Inner capital city & 0.12 & 0.14 & 0.14 & 0.14 \\
\hline Outer capital city & 0.27 & 0.26 & 0.26 & 0.26 \\
\hline Other urban & 0.25 & 0.25 & 0.25 & 0.23 \\
\hline Rural & 0.36 & 0.35 & 0.35 & 0.37 \\
\hline Education & & & & \\
\hline Less than year 10 & 0.32 & $0.39 * *$ & $0.39 * *$ & 0.35 \\
\hline Completed year 10 & 0.33 & 0.31 & 0.31 & 0.31 \\
\hline Completed year 11 & 0.08 & $0.07 * *$ & 0.08 & 0.09 \\
\hline Completed Year 12 & 0.13 & $0.10 * *$ & $0.10 * *$ & 0.12 \\
\hline More than Year 12 & 0.15 & $0.13 *$ & 0.12 & 0.13 \\
\hline Sample size & 1800 & 2940 & 2729 & 1082 \\
\hline
\end{tabular}


Table 2: Sample Sizes

and Data Issues

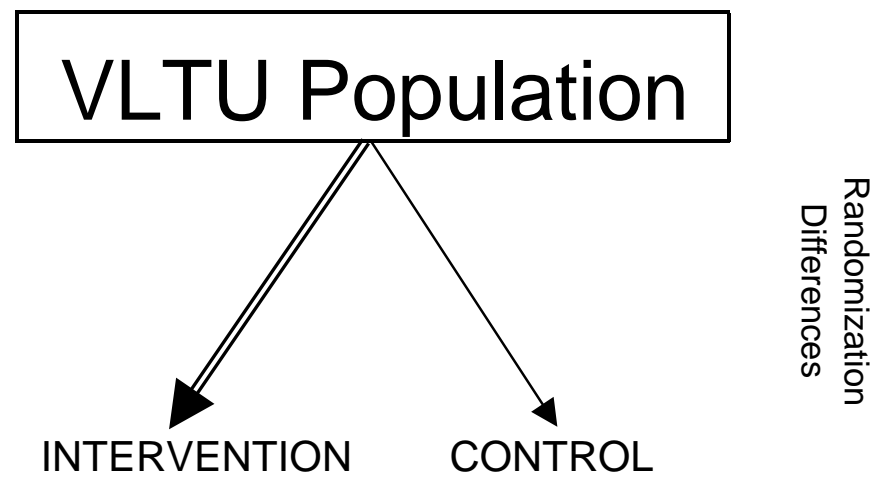

Letters Sent

Participated Wave 1

Participated Wave 2

Participated Wave 3

\begin{tabular}{|c|c|}
\hline 2940 & 1800 \\
\hline 1520 & 128 \\
\hline 1221 & $560^{\circ}$ \\
\hline 140 & 429 \\
\hline
\end{tabular}

Sample sizes for restricted subsamples of the intervention group

$\begin{array}{cc}\text { INTERVENTION } & \text { INTERVENTION } \\ \text { (AGE RESTRICTED) } & \text { (AGE \& PHONE } \\ & \text { RESTRICTED) }\end{array}$

Letters Sent

Participated Wave 1 Participated Wave 2

Participated Wave 3

\begin{tabular}{|c|c|}
\hline 2729 & 1082 \\
\hline 1373 & 578 \\
\hline 1097 & 473 \\
\hline 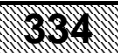 & 239 \\
\hline
\end{tabular}




\section{Table 3: Results from Intervention}

\section{Economic Participation Measures}

\begin{tabular}{lc}
$\begin{array}{l}\text { Average weekly hours working } \\
\text { Intervention }\end{array}$ & 3.64 \\
Control & 5.88 \\
& \\
Impact Estimate & $\mathbf{- 2 . 2 4} * * *$ \\
Standard Error & $\mathbf{( 0 . 7 5 )}$ \\
\hline
\end{tabular}

Average weekly hours looking for work

Intervention

Control

Impact Estimate

$-0.52$

Standard Error

(0.76)

Average weekly hours studying or training

Intervention

Control

1.57

Impact Estimate

$1.15 * *$

Standard Error

(0.55)

Average weekly hours all three above

Intervention

Control

14.97

Impact Estimate

$-1.31$

Standard Error

\section{Proportion working}

Intervention

0.299

Control

Impact Estimate

$-0.05$

Standard Error

(0.038)

Proportion looking for work

Intervention

0.751

Control

0.755

Impact Estimate

$-0.004$

Standard Error

\section{Proportion studying or training}

Intervention

0.176

Control

0.123

Impact Estimate

$0.053 *$

Standard Error

(0.030)

\section{Proportion any three above}

Intervention $\quad 0.841$

Control

0.846

Impact Estimate

Standard Error

(0.030)

\section{Voluntary and Social Participation Measures}

Average weekly hours voluntary work

Intervention

Control

Impact Estimate

0.49

Standard Error

(0.406)

Proportion Engaged in Voluntary Work

Intervention

0.236

Control

0.222

Impact Estimate

0.014

Standard Error

(0.035)

Proportion Socially Integrated

Intervention

Control

Impact Estimate

0.075

Standard Error

(0.038)

Cross-sectional propensity score matching estimates. Bandwidth for kernel match is 0.038 . Standard errors are bootstrapped.

***statistically significant at 1 per cent level; **statistically significant at 5 per cent level; *statistically significant at the 10 per cent level

Sample sizes vary due to missing data for some questions

Working: 234 Intervention, 402 Control.

Looking for work: 225 Intervention, 410 Control.

Studying/training: 239 Intervention, 429 Control.

Total economic activity: 220 Intervention, 387 Control.

Voluntary work: 236 Intervention, 425 Control.

Social integration: 239 Intervention, 429 Control. 


\section{Table 4: Results from Intervention \\ Age \& Phone Restricted Group}

Measures from Administrative Data

\begin{tabular}{|c|c|c|c|c|}
\hline & $\begin{array}{l}\text { All individuals assigned } \\
\text { to intervention and } \\
\text { control groups }\end{array}$ & $\begin{array}{l}\text { Wave } 3 \text { intervention grou } \\
\text { All individuals } \\
\text { assigned to control }\end{array}$ & $\begin{array}{l}\text { ants compared to: } \\
\text { Wave } 3 \text { Control } \\
\text { group participants }\end{array}$ & \\
\hline \multicolumn{5}{|c|}{ On payments during period June $1-28,2001$} \\
\hline Intervention & 0.916 & 0.983 & 0.983 & \\
\hline Control & 0.913 & 0.913 & 0.937 & \\
\hline $\begin{array}{l}\text { Impact Estimate } \\
\text { Standard Error }\end{array}$ & $\begin{array}{r}0.003 \\
(0.011) \\
\end{array}$ & $\begin{array}{r}\mathbf{0 . 0 7 0} \\
(\mathbf{0 . 0 1 9})\end{array}$ & $\begin{array}{r}0.046 \\
(0.017) \\
\end{array}$ & $* *$ \\
\hline \multicolumn{5}{|c|}{ Still on NewStart payment as of June $1-28,2001$} \\
\hline $\begin{array}{l}\text { Intervention } \\
\text { Control }\end{array}$ & $\begin{array}{l}0.773 \\
0.776\end{array}$ & $\begin{array}{l}0.854 \\
0.777\end{array}$ & $\begin{array}{l}0.854 \\
0.788\end{array}$ & \\
\hline $\begin{array}{l}\text { Impact Estimate } \\
\text { Standard Error }\end{array}$ & $\begin{array}{r}-0.003 \\
(0.016) \\
\end{array}$ & $\begin{array}{r}\mathbf{0 . 0 7 7} \quad * \\
(\mathbf{0 . 0 2 8})\end{array}$ & $\begin{array}{r}0.066 \\
(0.032) \\
\end{array}$ & $* *$ \\
\hline \multicolumn{5}{|c|}{ Has earnings during period June 1-28, 2001} \\
\hline $\begin{array}{l}\text { Intervention } \\
\text { Control }\end{array}$ & $\begin{array}{l}0.212 \\
0.236\end{array}$ & $\begin{array}{l}0.268 \\
0.236\end{array}$ & $\begin{array}{l}0.268 \\
0.286\end{array}$ & \\
\hline $\begin{array}{l}\text { Impact Estimate } \\
\text { Standard Error }\end{array}$ & $\begin{array}{r}-0.024 \\
(0.017) \\
\end{array}$ & $\begin{array}{r}\mathbf{0 . 0 3 2} \\
(\mathbf{0 . 0 3 0}) \\
\end{array}$ & $\begin{array}{r}-\mathbf{0 . 0 1 8} \\
(0.037) \\
\end{array}$ & \\
\hline \multicolumn{5}{|c|}{ Average earnings during period June 1-28, 2001} \\
\hline $\begin{array}{l}\text { Intervention } \\
\text { Control }\end{array}$ & $\begin{array}{l}54.06 \\
60.14\end{array}$ & $\begin{array}{l}70.46 \\
60.15\end{array}$ & $\begin{array}{l}70.46 \\
82.83\end{array}$ & \\
\hline $\begin{array}{l}\text { Impact Estimate } \\
\text { Standard Error }\end{array}$ & $\begin{array}{r}-6.08 \\
(6.89) \\
\end{array}$ & $\begin{array}{r}10.31 \\
(11.99) \\
\end{array}$ & $\begin{array}{r}-12.37 \\
(16.17) \\
\end{array}$ & \\
\hline \multicolumn{5}{|c|}{ Average earnings (for those with earnings) during period June 1-28, 2001} \\
\hline $\begin{array}{l}\text { Intervention } \\
\text { Control }\end{array}$ & $\begin{array}{l}255.55 \\
254.71\end{array}$ & $\begin{array}{l}262.84 \\
254.72\end{array}$ & $\begin{array}{l}262.84 \\
289.58\end{array}$ & \\
\hline $\begin{array}{l}\text { Impact Estimate } \\
\text { Standard Error }\end{array}$ & $\begin{array}{r}0.84 \\
(24.14) \\
\end{array}$ & $\begin{array}{r}8.12 \\
(36.85) \\
\end{array}$ & $\begin{array}{r}-26.74 \\
(45.07) \\
\end{array}$ & \\
\hline
\end{tabular}

**statistically significant at 5 per cent level; *statistically significant at the 10 per cent level.

Sample sizes are as follows:

Column 2: 1082 assigned intervention and 1800 assigned control; 988 intervention and 1643 control in LDS June 2001; 209 intervention and 388 control with earnings

Column 3: 239 Wave 3 intervention and 1800 assigned control; 235 Wave 3 intervention and 1643 control in LDS June 2001; 209 intervention and 388 control with earnings

Column 4: 239 Wave 3 intervention and 429 Wave 3 control; 235 Wave 3 intervention and 402 Wave 3 control in LDS June 2001; 63 intervention and 115 control with earnings 


\section{Appendix 1}

Table A1: Determinants of Participation in Wave 3 Age \& Phone Restricted Group

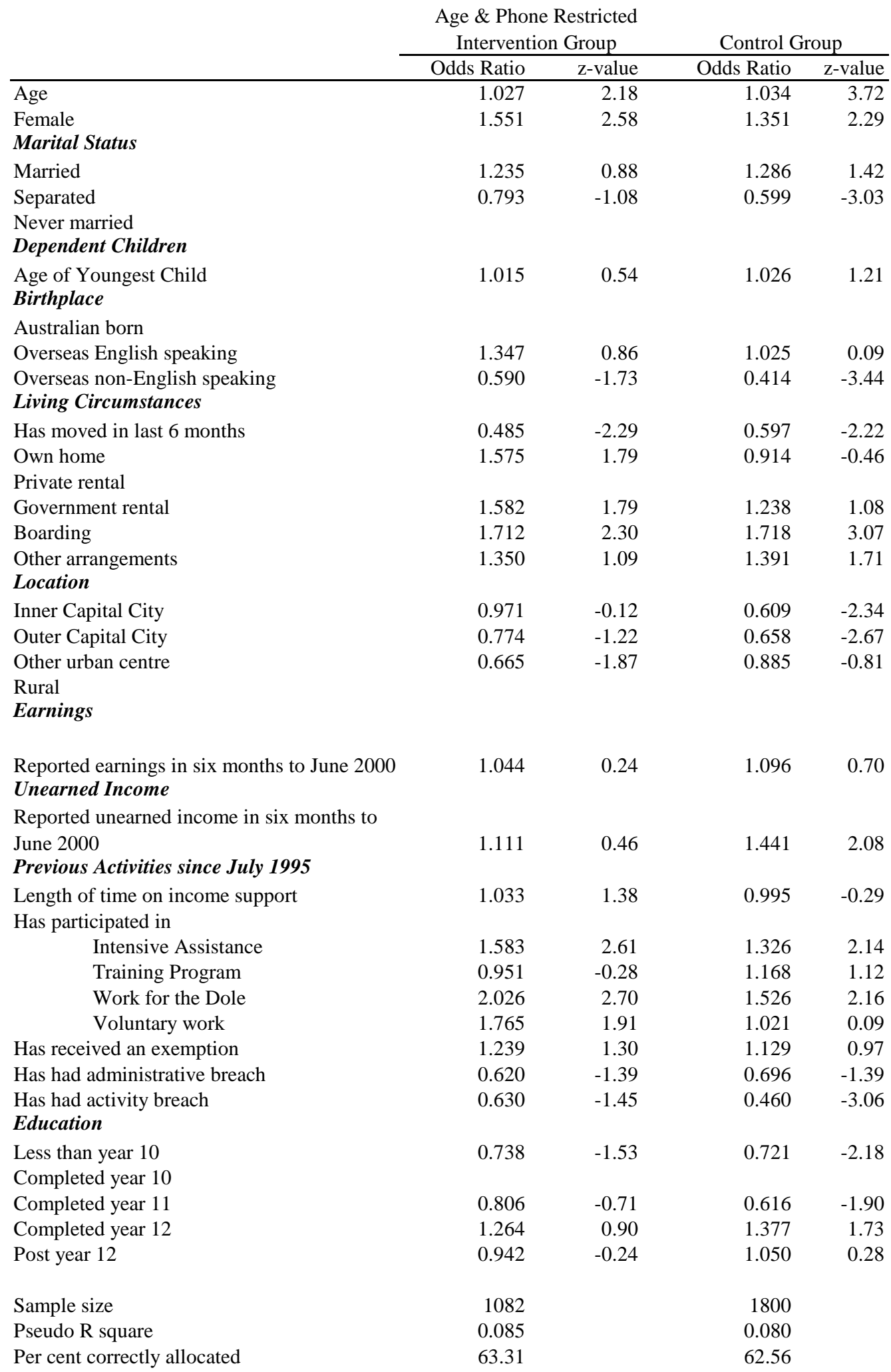


Table A2: Economic Participation Measures (Levels)

Age \& Phone Restricted Group

\begin{tabular}{|c|c|c|c|c|c|}
\hline Group & Wave 1 & $\begin{array}{l}\text { ndomized Exp } \\
\text { Wave } 3\end{array}$ & $\begin{array}{l}\text { periment } \\
\text { Difference-in- } \\
\text { Difference } \\
\end{array}$ & $\begin{array}{c}\text { Propensity Scor } \\
\text { Wave } 3\end{array}$ & $\begin{array}{l}\text { e Matching }^{a} \\
\text { Difference-in- } \\
\text { Difference }\end{array}$ \\
\hline \multicolumn{6}{|c|}{ Economic Participation Measures } \\
\hline \multicolumn{6}{|c|}{ Average weekly hours working } \\
\hline Intervention & 3.13 & 3.64 & 0.51 & 3.64 & 0.52 \\
\hline Control & 4.51 & 5.78 & 1.27 & 5.88 & 1.28 \\
\hline $\begin{array}{l}\text { Impact Estimate } \\
\text { Standard Error }\end{array}$ & & $\begin{array}{l}-2.14 * * * \\
(0.75)\end{array}$ & $\begin{array}{r}-0.76 \\
(0.63)\end{array}$ & $\begin{array}{l}-2.24 * * * \\
(0.75)\end{array}$ & $\begin{array}{r}-0.76 \\
(0.66)\end{array}$ \\
\hline \multicolumn{6}{|c|}{ Average weekly hours looking for work } \\
\hline Intervention & 6.59 & 7.04 & 0.45 & 7.04 & 0.44 \\
\hline Control & 8.92 & 7.66 & -1.26 & 7.56 & -1.30 \\
\hline $\begin{array}{l}\text { Impact Estimate } \\
\text { Standard Error } \\
\end{array}$ & & $\begin{array}{r}-0.62 \\
(0.74) \\
\end{array}$ & $\begin{array}{l}1.71 * \\
(0.98) \\
\end{array}$ & $\begin{array}{r}-0.52 \\
(0.76) \\
\end{array}$ & $\begin{array}{c}1.74 * \\
(1.01) \\
\end{array}$ \\
\hline \multicolumn{6}{|c|}{ Average weekly hours studying or training } \\
\hline Intervention & 1.51 & 2.72 & 1.21 & 2.72 & 1.21 \\
\hline Control & 1.80 & 1.59 & -0.21 & 1.57 & -0.22 \\
\hline $\begin{array}{l}\text { Impact Estimate } \\
\text { Standard Error }\end{array}$ & & $\begin{array}{l}1.13 \text { ** } \\
(0.56)\end{array}$ & $\begin{array}{l}1.42 * * \\
(0.65)\end{array}$ & $\begin{array}{l}1.15 * * \\
(0.55) \\
\end{array}$ & $\begin{array}{l}1.43 \\
(0.65) \\
\end{array}$ \\
\hline \multicolumn{6}{|c|}{ Average weekly hours all three above } \\
\hline Intervention & 10.82 & 13.65 & 2.83 & 13.65 & 2.83 \\
\hline Control & 15.12 & 15.05 & -0.07 & 14.97 & -0.06 \\
\hline $\begin{array}{l}\text { Impact Estimate } \\
\text { Standard Error }\end{array}$ & & $\begin{array}{r}-1.40 \\
(1.14) \\
\end{array}$ & $\begin{array}{c}2.90 \\
(\mathbf{1 . 2 4})\end{array}$ & $\begin{array}{r}-1.31 \\
(1.16) \\
\end{array}$ & $\begin{array}{c}2.89 \\
(1.32) \\
\end{array}$ \\
\hline
\end{tabular}

a. Bandwidth for kernel match is 0.038 . Standard errors are bootstrapped.

*** statistically significant at 1 per cent level; **statistically significant at 5 per cent level; * statistically significant at the 10 per cent level

Sample sizes vary due to missing data for some questions

Weekly hours working: 234 Intervention, 402 Control.

Weekly hours looking for work: 225 Intervention, 410 Control.

Weekly hours studying/training: 239 Intervention, 429 Control.

Total economic activity: 220 Intervention, 387 Control. 
Table A3: Economic Participation Measures (Proportions)

Age \& Phone Restricted Group

\begin{tabular}{|c|c|c|c|c|c|}
\hline Group & Wave 1 & $\begin{array}{l}\text { ndomized } E \\
\text { Wave } 3\end{array}$ & $\begin{array}{l}\text { periment } \\
\text { Difference-in- } \\
\text { Difference } \\
\end{array}$ & $\mid \begin{array}{c}\text { Propensity Sc } \\
\text { Wave } 3\end{array}$ & $\begin{array}{l}\text { Matching }^{a} \\
\text { Difference-in- } \\
\text { Difference }\end{array}$ \\
\hline \multicolumn{6}{|c|}{ Economic Participation Measures } \\
\hline Proportion work & & & & & \\
\hline Intervention & 0.274 & 0.299 & 0.025 & 0.299 & 0.026 \\
\hline Control & 0.301 & 0.341 & 0.040 & 0.349 & 0.042 \\
\hline $\begin{array}{l}\text { Impact Estimate } \\
\text { Standard Error }\end{array}$ & & $\begin{array}{r}-0.042 \\
(0.038) \\
\end{array}$ & $\begin{array}{r}-0.015 \\
(0.032) \\
\end{array}$ & $\begin{array}{r}-0.05 \\
(0.038) \\
\end{array}$ & $\begin{array}{r}-0.016 \\
(0.033) \\
\end{array}$ \\
\hline \multicolumn{6}{|c|}{ Proportion looking for work } \\
\hline Intervention & 0.827 & 0.751 & -0.076 & 0.751 & -0.076 \\
\hline Control & 0.781 & 0.759 & -0.022 & 0.755 & -0.024 \\
\hline $\begin{array}{l}\text { Impact Estimate } \\
\text { Standard Error }\end{array}$ & & $\begin{array}{r}-0.008 \\
(0.036) \\
\end{array}$ & $\begin{array}{r}-0.054 \\
(0.036) \\
\end{array}$ & $\begin{array}{r}-0.004 \\
(0.036) \\
\end{array}$ & $\begin{array}{r}-0.052 \\
(0.038) \\
\end{array}$ \\
\hline \multicolumn{6}{|c|}{ Proportion studying or training } \\
\hline Intervention & 0.105 & 0.176 & 0.071 & 0.176 & 0.071 \\
\hline Control & 0.126 & 0.124 & -0.002 & 0.123 & -0.001 \\
\hline $\begin{array}{l}\text { Impact Estimate } \\
\text { Standard Error }\end{array}$ & & $\begin{array}{l}0.052 \\
(\mathbf{0 . 0 2 9}) \\
\end{array}$ & $\begin{array}{l}\mathbf{0 . 0 7 3} * * \\
(\mathbf{0 . 0 3 3}) \\
\end{array}$ & $\begin{array}{c}0.053 \\
(\mathbf{0 . 0 3 0}) \\
\end{array}$ & $\begin{array}{l}\mathbf{0 . 0 7 2} \\
(\mathbf{0 . 0 3 3}) \\
\end{array}$ \\
\hline \multicolumn{6}{|c|}{ Proportion any three above } \\
\hline Intervention & 0.859 & 0.841 & -0.018 & 0.841 & -0.018 \\
\hline Control & 0.840 & 0.850 & 0.010 & 0.846 & 0.007 \\
\hline $\begin{array}{l}\text { Impact Estimate } \\
\text { Standard Error }\end{array}$ & & $\begin{array}{r}-0.009 \\
(0.031)\end{array}$ & $\begin{array}{r}-0.028 \\
(0.027)\end{array}$ & $\begin{array}{r}-0.005 \\
(0.030)\end{array}$ & $\begin{array}{r}-0.026 \\
(0.028)\end{array}$ \\
\hline
\end{tabular}

a. Bandwidth for kernel match is 0.038 . Standard errors are bootstrapped.

*** statistically significant at 1 per cent level; **statistically significant at 5 per cent level; *statistically significant at the 10 per cent level Sample sizes vary due to missing data for some questions

Weekly hours working: 234 Intervention, 402 Control.

Weekly hours looking for work: 225 Intervention, 410 Control.

Weekly hours studying/training: 239 Intervention, 429 Control.

Total economic activity: 220 Intervention, 387 Control. 
Table A4: Voluntary and Social Participation Age \& Phone Restricted Group

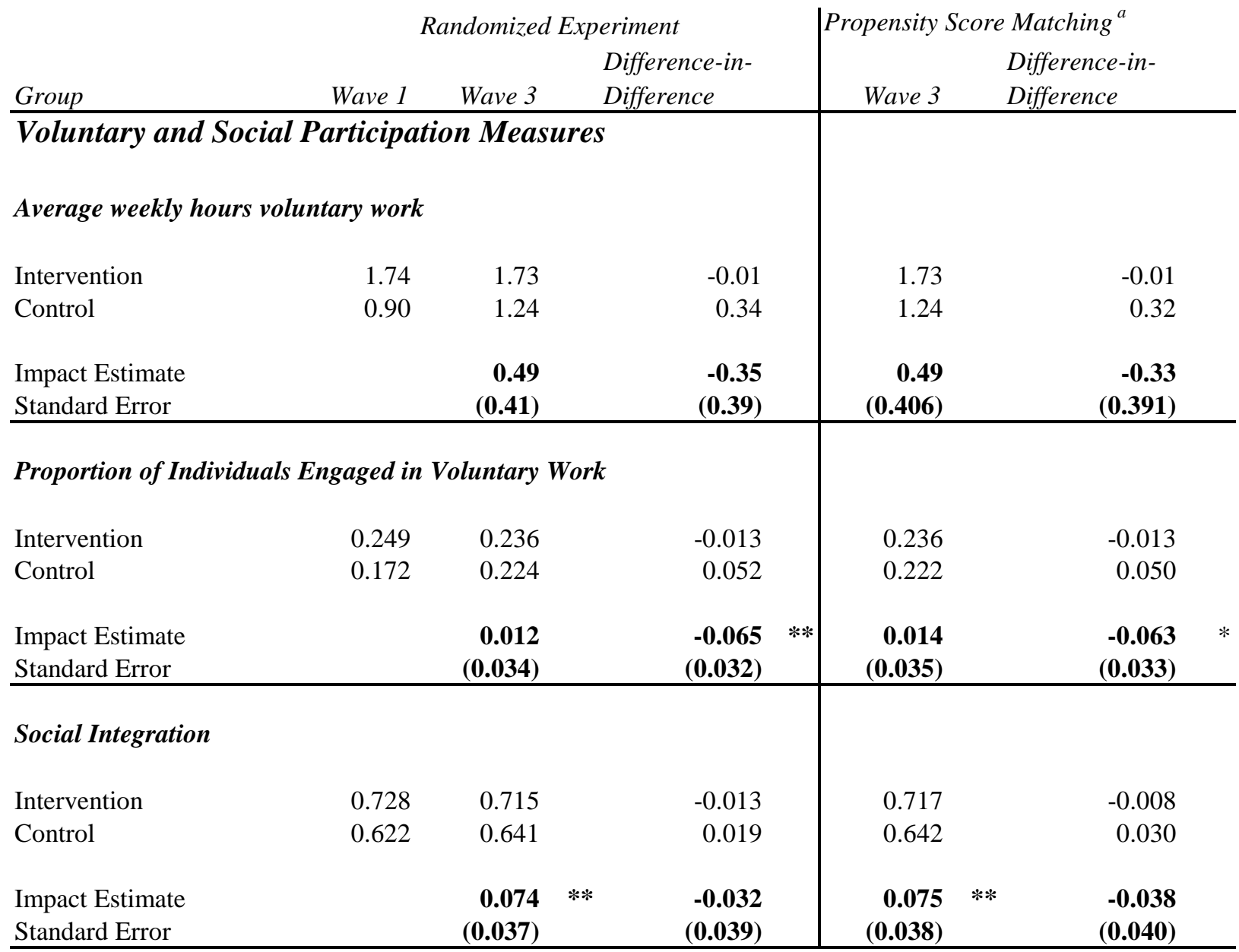

a. Bandwidth for kernel match is 0.038 . Standard errors are bootstrapped.

*** statistically significant at 1 per cent level; **statistically significant at 5 per cent level; *statistically significant at the 10 per cent level Sample sizes for Voluntary Work measures: 236 Intervention, 425 Control.

Sample sizes for Social Participation: 239 Intervention, 429 Control. 


\section{APPENDIX 2 \\ Letter sent to individuals selected into intervention group}

\section{$\underline{\text { Intervention group letter }-1^{\text {ST }} \text { INTERVIEW }}$}

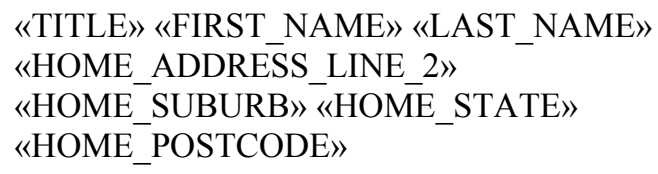

Dear «TITLE»«LAST_NAME»,

I am writing to you to let you know you are required to attend an interview to discuss employment assistance options that may be available to you and to check that you are getting the right amount of Newstart Allowance. We will also discuss with you any plans you may have for the future and how we can help you.

As part of a new pilot programme, we are especially interested in finding out more about people in situations similar to yours and whether they might like more help in gettting access to services that are helpful to them. This pilot programme is confidential.

At this interview you will be required to negotiate and sign a Preparing for Work Agreement which will include activities you will undertake in order to maximise your chances of finding work.

If you do not attend this interview or make other arrangements, your payments will be stopped and a penalty will apply when you reclaim payments. If your payments are stopped we will write to you about this.

You need to ring the Centrelink Call Centre on $X X X X$ within the next 14 days to make an appointment with a customer service officer. If, after you have booked an appointment, you cannot attend the interview please get in touch with us as soon as possible to make new arrangements. Our address and phone number are at the top of this letter.

If you have a Jobseeker diary, please bring it and this letter to the interview.

Yours sincerely, 


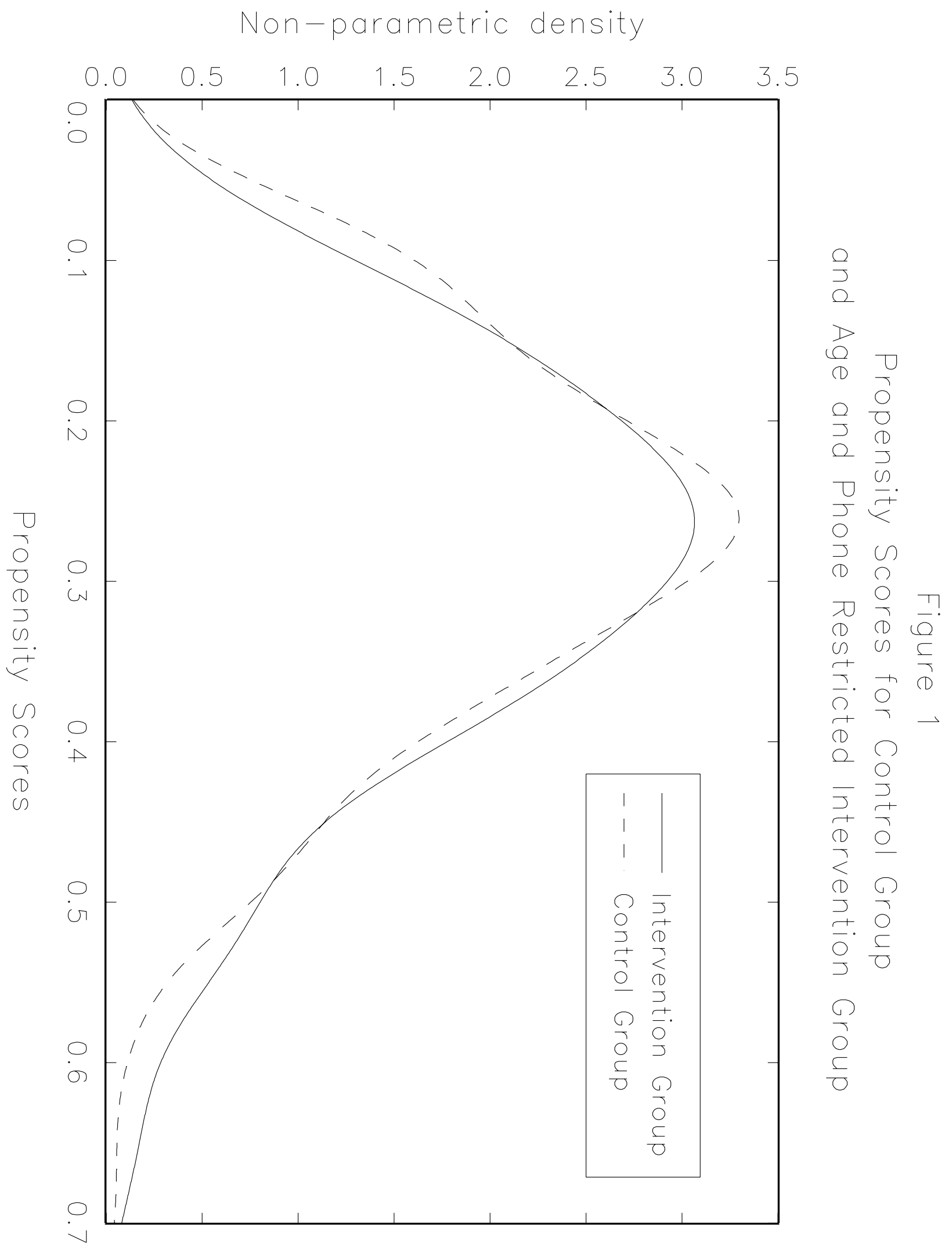

